\title{
COMPREENSÃO DA PAISAGEM DO ALTO CAMAQUÃ: debate ambiental sobre o Bioma Pampa
}

the understanding of the landscape of the Alto Camaquã: environmental debate of the Pampa Biome

\author{
Adriano Severo Figueiró* \\ Jaciele Carine Sell** \\ Marilse Beatriz Losekann*** \\ Simone Marafiga Degrandi****
}

\begin{abstract}
Resumo
O presente artigo aborda a configuração da paisagem da sub-bacia do Alto Camaquã/RS, bem como a evolução de determinados elementos naturais e histórico-culturais que tornaram esta uma das mais belas e intrigantes paisagens que compõem o território gaúcho e o denominado Bioma Pampa. Este recorte de estudo foi determinado em função de sua importância para a conservação e proteção deste bioma brasileiro ameaçado pela introdução de formas de "desenvolvimento exógeno" atualmente adotadas e que não estão de acordo com as particularidades socioeconômicas, culturais e ambientais da região. Neste sentido, o trabalho busca discutir as particularidades existentes e o condicionamento que os elementos naturais desta paisagem representam para o processo de apropriação e ordenamento territorial do Pampa.
\end{abstract}

Palavras-chave: Paisagem, Bioma Pampa, Alto Camaquã.

\begin{abstract}
This article discusses the landscape configuration of the sub-basin of Alto Camaquã/RS, as well as the evolution of certain natural and historical-cultural elements that made this one of the most beautiful and intriguing landscapes that make up the gaucho's territory and the denominated Pampa Biome. The delimitation of the study was determined according to its importance for the conservation and protection of Brazilian biome, threatened by the introduction of "exogenous development" forms currently adopted and which are not according to the socioeconomics, cultural and environmental particularities of the region. In this sense, the central objective of the paper is to discuss the particularities and the conditioning that the natural elements of this landscape represent to the process of ownership and management of land in the Pampa Biome.
\end{abstract}

Key words: Landscape, Pampa Biome, Alto Camaquã.

\section{Resumen}

El presente articulo trata de la configuración del paisaje de la subcuenca del Alto Camaquã/RS, bien como la evolución de determinados elementos naturales y la historia de las culturas que tornaran esta una de las más bellas e intrigantes paisajes que componen el territorio gaucho y el denominado Bioma Pampa. Este recorte de estudio fue determinado en función de su importancia para la conservación y protección de este bioma brasilero amenazado por la introducción de formas de "desarrollo exógeno" actualmente aprobadas y que no están de acuerdo con las particularidades socioeconómicas, culturales y ambientales de la región. En este sentido, el documento analiza las particularidades existentes y condicionamiento que los elementos naturales de este paisaje representan para el proceso de propiedad y planificación territorial del Pampa.

Palabras clave: Paisaje, Bioma Pampa, Alto Camaquã.

(*) Prof. Dr. da Pós-Graduação em Geografia da Universidade Federal de Santa Maria - Cid. Univ., Av. Roraima n¹000, CEP 97105-900, Camobi-Santa Maria (RS), Brasil, Tel: (+ 5555 ) 32209446 - adri.geo.ufsm@gmail.com

(**) Mestranda do Programa de Pós-graduação em Geografia da Federal de Santa Maria - Cid. Univ., Av. Roraima n¹000, CEP 97105-900, Camobi-Santa Maria (RS), Brasil, Tel: (+ 5555 ) 32209446 - jacics@gmail.com

(***) Mestranda do Programa de Pós-graduação em Geografia da Federal de Santa Maria - Cid. Univ., Av. Roraima nº00, CEP 97105-900, Camobi-Santa Maria (RS), Brasil, Tel: (+ 5555 ) 32209446 - marilosekann@hotmail.com

(****) Mestranda do Programa de Pós-graduação em Geografia da Federal de Santa Maria - Cid. Univ., Av. Roraima nº 1000, CEP 97105-900, Camobi-Santa Maria (RS), Brasil, Tel: (+ 5555 ) 32209446 - simone5z@yahoo.com.br 


\section{INTRODUÇÃO}

A paisagem extremamente singular da metade sul do Rio Grande do Sul tem sido alvo de acalorados debates com relação a seu futuro. Diferentes modelos de desenvolvimento vêm sendo propostos pelo poder público, pela iniciativa privada e pela sociedade organizada. Dentre estes, cabe destacar o modelo agro-exportador baseado no latifúndio monocultor, através da implantação da silvicultura (espécies exóticas) e, por outro lado, propostas de desenvolvimento endógeno que vêm sendo discutidas por órgãos públicos (Universidades e EMBRAPA ) visando o desenvolvimento das potencialidades da paisagem local, a partir de um modelo de sustentabilidade que articule a fragilidade do meio com os saberes tradicionais envolvidos no processo histórico de apropriação desta área.

Em conseqüência do modelo de monocultura de árvores exóticas já estar sendo implantado, sem respeitar as restrições recomendadas pelos órgãos ambientais responsáveis, resta uma profunda preocupação com à evolução da paisagem e a construção de cenários futuros deste território . A categoria de análise geográfica que melhor se adapta a essa abordagem é a paisagem, dada a sua capacidade de abrangência dos diversos fatores envolvidos nas dinâmicas territoriais em curso.

Neste sentido, o estudo da dinâmica da paisagem envolve não somente o que é visível ao olho humano, mas também a compreensão de todas as forças que, por uma razão ou outra, não se manifestam de forma evidente nesta estrutura visível. Além disso, como afirmam Romero e Jiménez (2002), a forma e a estrutura que vemos na atualidade, são o reflexo das dinâmicas do passado, fazendo com que o tempo acabe se tornando um elemento fundamental na determinação dos controles que definem o ritmo e a forma das transformações estruturais e que, na maior parte das vezes, não é considerado.

\section{O BIOMA PAMPA E O ALTO CAMAQUÃ}

O Brasil faz parte dos países que possuem maior megadiversidade do mundo (Barthlott et. al. apud Overbeck et. al., 2009), mas também possui essa diversidade extremamente ameaçada e consideravelmente desconhecida. A paisagem brasileira pode ser dividida em seis grandes biomas, de acordo com a classificação feita pelo IBGE (2004) - Amazônia, Mata Atlântica, Caatinga, Cerrado, Pantanal e Pampa - sendo que a maioria possui deficiência quanto às informações sobre sua fauna e flora (Overbeck, 2009).

O Bioma Pampa, objeto de estudo deste trabalho, caracteriza-se por ser um mosaico de vegetação campestre e arbustiva - campos limpos e campos sujos (Overbeck, 2009) -, submetido a características macroestruturais - condições climáticas e de geologia - únicas, o que gera, inclusive, uma discussão acerca da sua denominação .

O Pampa, segundo Suertegaray e Pires da Silva (2009), abrange regiões pastoris de planícies nos três países da América do Sul - cerca de dois terços do estado do Rio Grande do Sul (17,6 milhões de hectares da metade sul do estado), além das províncias argentinas de Buenos Aires, La Pampa, Santa Fé, Entrerríos e Corrientes e a totalidade da República Oriental do Uruguai. (Figura 1).

Este bioma (IBGE apud Suertegaray e Pires da Silva, 2009), é a reunião de "formações ecológicas que se inter-cruzam em uma formação ecopaisagística única, com intenso tráfego de matéria, energia e vida entre os campos, matas ciliares (de galeria), capões de mato e matas de encostas". (p.43) 


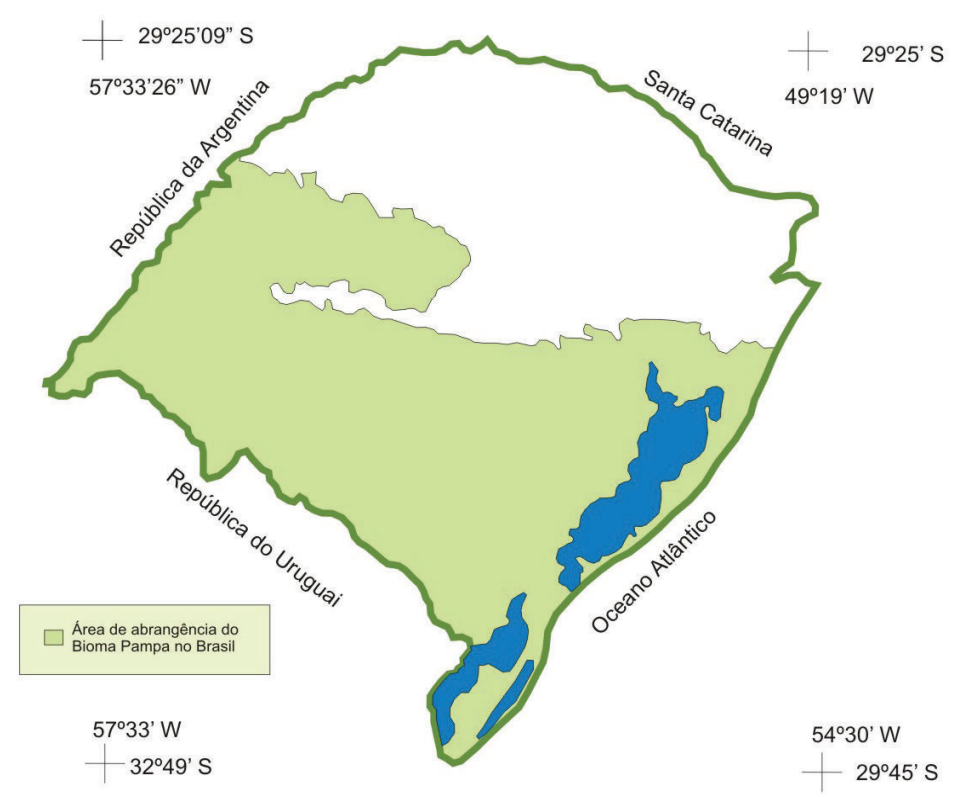

Figura 1 - Área de abrangência do Bioma Pampa no Brasil Fonte: Instituto Brasileiro de Geografia e Estatística Org.: Sell, J.C.

No entanto, desta sua vegetação campestre natural e dos seus banhados característicos, restam apenas 39\% (Picolli e Schnadelbach, 2007). Entre os anos de 1970 e 2005, segundo as autoras (op. cit.), estima-se que 4,7 milhões de hectares de pastagens nativas tenham sido convertidos em outros usos agrícolas, como lavouras e plantações de árvores exóticas.

Esta violenta supressão da vegetação campestre natural do Pampa gaúcho torna-se ambientalmente ainda mais grave diante da imensa riqueza da biodiversidade nela existente. Estimativas recentes indicam que esta região é composta de pelo menos 3.000 plantas vasculares, com 450 espécies de gramíneas e 150 de leguminosas, além de 385 aves e 90 mamíferos, sendo parte destas espécies chamadas endêmicas, pois só ocorrem neste ecossistema. É por isto que os campos pampeanos, na sua composição de flora e fauna, podem ser considerados tão importantes quanto uma floresta tropical, para a conservação da biodiversidade planetária. (PICOLLI e SCHNADELBACH, 2007).

Todas essas alterações que vem ocorrendo no Bioma Pampa refletem conseqüentemente, na paisagem do Alto Camaquã . O Alto Camaquã está localizado na metade sul do estado do Rio Grande do Sul, compreendendo o terço superior da bacia do Rio Camaquã, situado na Serra do Sudeste do Rio Grande do Sul.

Esta porção do território gaúcho engloba os municípios de Caçapava do Sul, Santana da Boa Vista, Piratini, Lavras do Sul, Bagé, Pinheiro Machado e, em menores proporções, os municípios de Dom Pedrito e Hulha Negra (figura 2), compondo uma área total de $8.300 \mathrm{~km}^{2}$, onde vive uma população predominantemente rural de aproximadamente 35 mil habitantes (FEPAM, 2006) tendo como base de sua economia, a agricultura e a pecuária. 


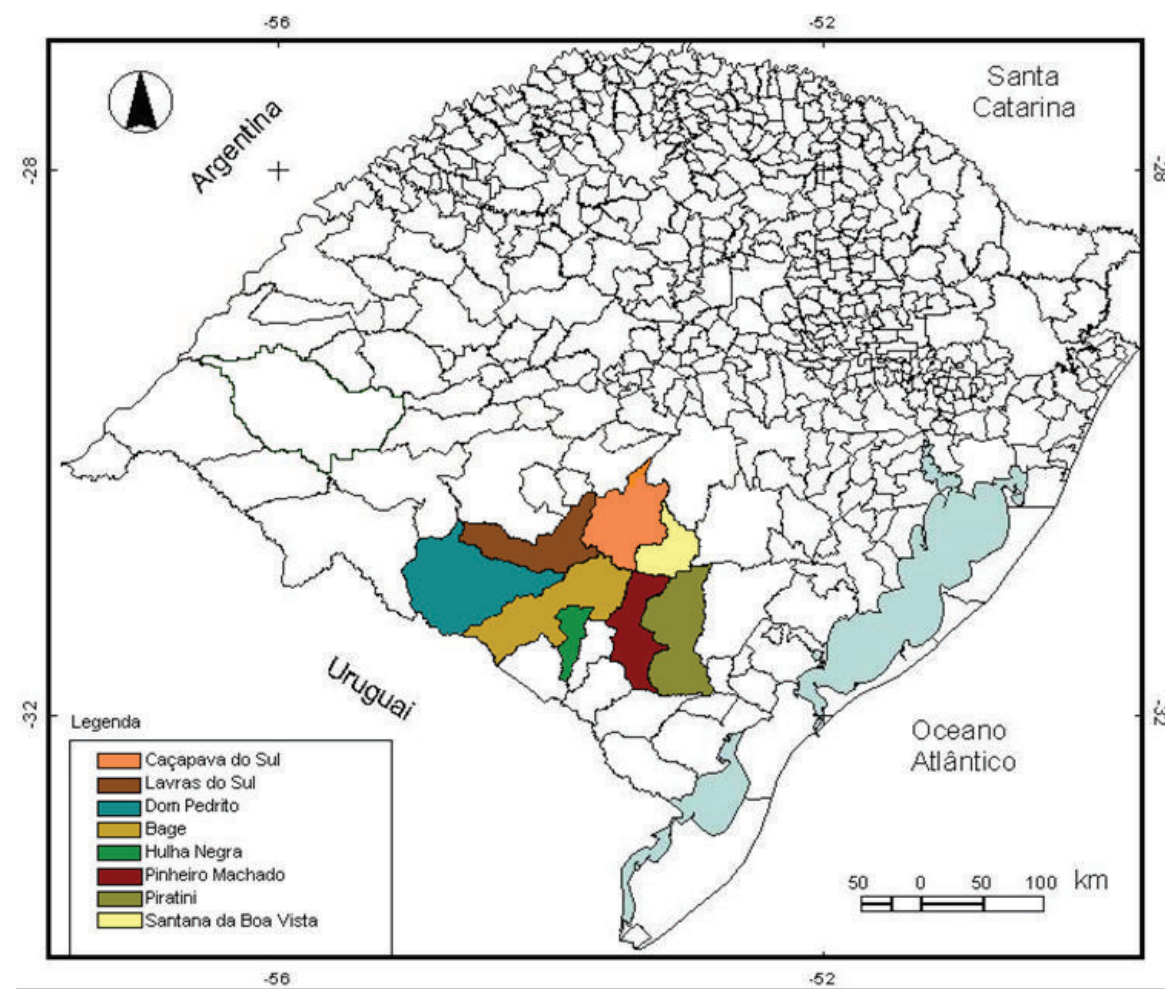

Figura 2 - Mapa de localização dos municípios que compõem o Alto Camaquã/RS. Org. - Degrandi, S. M., (2009).

\section{A CONFIGURAÇÃO DA PAISAGEM NO ALTO CAMAQUÃ}

Ao analisar a paisagem não basta apenas descrever as suas características visíveis, mas sim todo processo interno e externo que influencia uma determinada unidade. Sendo assim, a análise sistêmica é a que, segundo Romero e Jiménez (2002), melhor se adapta para um real conhecimento de um território, de uma paisagem. No entanto, os autores (op. cit.) afirmam que, mesmo defendendo uma explicação integrada da paisagem, é preciso conhecer os elementos e componentes em sua particularidade, a fim de buscar compreender as suas interconexões. Esses elementos, de acordo com Bertrand (1972), podem ser distribuídos em 7 classes ou componentes - morfoestruturais, climáticos, morfoesculturais ou geomorfológicos, hidrológicos, antrópicos, cobertura vegetal e cobertura edáfica. Tais componentes podem ser agrupados, ainda, em outros três subsistemas, o antrópico, o biótico e o abiótico.

Desse modo, do ponto de vista dos aspectos naturais, a sub-bacia do Alto Camaquã, por estar inserida no Bioma Pampa, revela uma combinação particular de elementos abióticos (rochas, solo, clima, relevo, etc) com uma diversidade biológica muito presente (fauna, flora), sendo a associação destas características responsável por uma beleza paisagística inusitada. Estas particularidades da paisagem encontrada no Alto Camaquã revelam a existência de um grande patrimônio natural e histórico-cultural a ser preservado.

Ainda sobre este aspecto, Neske (2009), revela que o Padre Balduíno Rambo em sua viagem de estudos fitogeográficos na década de 1940 pela região impressionou-se e registrou em seus documentos tamanha beleza, pois, segundo ele, os "vales cercados de paredões abruptos e encostas íngremes cobertas de lajes desabadas presentes no Alto Camaquã formam a paisagem mais bela de tantas que existem na borda da Serra do Sudeste" (RAMBO apud Neske, p. 73, 2009).

As características culturais e socioeconômicas extremamente particulares do território do Alto Camaquã tornaram a modernização tecnológico-produtiva não expressiva em comparação a outras regiões do estado. O contexto local, incompatível com as estratégias de modernização e "desenvolvimento" advindas com a Revolução Verde, a partir dos anos 60, demonstrou a impossibilidade de 
adotar modelos produtivos mecanizados nesta região. Este fato tem historicamente marginalizado esta porção do território gaúcho, comumente designada como tecnologicamente atrasada e socioeconomicamente subdesenvolvida, levando a uma estigmatização que se projeto, inclusive, sobre a auto-estima das populações locais.

Essa realidade social e ecológica complexa é resultado de uma "modernização incompleta". Em decorrência disso, de acordo com a EMBRAPA (2008/09) é possível caracterizar as formas de produção presentes no Alto Camaquã como predominantemente pecuárias e de escala familiar, caracterizando uma produção camponesa, dada a predominância do uso de elementos que entram no processo produtivo como "não-mercadoria". Uma condição que determina que a produção pecuária do Alto Camaquã mantenha relações mais intensas com a natureza do que com o mercado, proporcionando uma interdependência de tal ordem entre produção e recursos naturais, que impediu a degradação ambiental que se evidencia nas demais regiões do estado.

As intervenções e transformações significativas na paisagem do Alto Camaquã se intensificaram efetivamente a partir de 1740, com a vinda de colonos portugueses, principalmente açorianos, que eram, nas suas ilhas de origem, agricultores e, em escala menor, criadores de gado; portanto, nada mais natural do que transplantarem, de acordo com as ilimitadas possibilidades da nova pátria, suas ocupações tradicionais. (RAMBO, 1994).

Antes de uma descrição mais detalhada da paisagem do Alto Camaquã, cabe salientar que, assim como afirmam Romero e Jiménez (2002), encostas íngremes os elementos naturais que a compõe não possuem o mesmo grau de importância, ou seja, não estão no mesmo plano (op. cit.). Existe uma evidente hierarquia entre os componentes e elementos da paisagem na manutenção do seu controle estrutural, e não considerá-la, seria como "empezar la casa por el tejado". (ROMERO e JIMÉNEZ, p. 36, 2002.).

"La escala de manifestación de cada componente se encuentra altamente correlacionada con su estabilidad y susceptibilidad para ser influenciado por otros componentes, estableciéndose de esta forma la jerarquía natural entre ellos y diferenciándose los que son claves del funcionamiento del paisaje y aquéllos de menor importancia que están subordinados a los primeros.(ROMERO E JIMÉNEZ, 2002, p.35)"

Ao referir-se a estrutura e hierarquia da paisagem, Romero e Jiménez (2002) dividem os seus componentes em dois grandes sub-grupos: as macroestruturas e as mesoestruturas. As primeiras possuem menor suscetibilidade a mudança (mais independentes) e são compostas pela estrutura geológica e pelo clima. As macroestruturas apresentam estabilidade e independência e definem a estrutura básica do território, onde irão se assentar e se sobrepor os demais componentes que se manifestam na paisagem. (op. cit.). Já as mesoestruturas compõe-se dos demais elementos constituintes da paisagem, como água, solo, vegetação, fauna, relevo e intervenção antrópica. São os elementos mais dinâmicos e vulneráveis de uma paisagem e, conforme os autores (op. cit.) dependem da matéria e da energia controladas pelas macroestruturas.

No decorrer dos próximos parágrafos, portanto, buscar-se-á descrever os principais elementos que compõe esta paisagem do Alto Camaquã e demonstrar o grau de dependência de um elemento com relação ao outro. É preciso destacar o fato de que a unidade de análise refere-se ao terço superior da bacia hidrográfica do Rio Camaquã estando, então, inserida dentro de outras unidades maiores (Bioma Pampa) e sendo composta de unidades menores de paisagem (unidades de paisagem estabelecidas pelo Zoneamento Ambiental - FEPAM, 2007).

O Alto Camaquã é uma região que, conforme apontam os mapas elaborados pela FEPAM (2007) para o Zoneamento Ambiental do Rio Grande do Sul, apresenta alta deficiência hídrica no solo nos meses de verão, além de ser, também, a região do estado que apresenta menor disponibilidade hídrica superficial. Essa característica exige atenção com relação ao uso do solo, principalmente no que se refere ao tipo de atividade agrícola . No entanto, tais informações não vêm sendo levadas 
em consideração quando da formulação das políticas públicas ambientais e/ou econômicas criadas e implantadas para essa região, a exemplo das monoculturas de espécies exóticas.

Esta interferência antrópica ocorre através da proposta do poder público como modelo de desenvolvimento para o Pampa, que significa uma mudança radical de sua matriz produtiva, passando da atividade pecuária nos campos a uma intensa exploração da silvicultura.

Para além das já históricas e aceleradas taxas de conversão de áreas nativas do Pampa em espaços agricultáveis (tabela 1), ambientalistas e pesquisadores das Instituições Federais de Ensino Superior do Rio Grande do Sul vêm alertando sobre os prejuízos que essas lavouras de eucalipto podem gerar para a área.

Em primeiro lugar está o fato de um bioma de campo, como é o Bioma Pampa, possuir solo, clima e características socioambientais impróprias para florestamento com espécies exóticas, como o eucalipto, o pinus e a acácia. A partir disso, desencadeiam-se inúmeras outras questões ambientais, como a impossibilidade de associação de culturas, "ressecamento" de reservatórios hídricos, destruição de habitats das espécies locais, perda da biodiversidade, desestruturação de comunidades rurais, êxodo rural e crescimento da pobreza urbana, concentração de terra e capital, diminuição de postos de trabalho, geração de vazios demográficos.

Neste novo modelo, é inevitável um forte aumento da concentração de terras na região, que nas mãos de poucas grandes empresas, serão convertidas em extensas plantações de árvores. Estes maciços de árvores abastecerão produtoras de polpa de celulose, a qual será na maior parte exportada para fábricas de papel européias.

Tabela 1 - Conversão de campos nativos do Bioma Pampa em áreas agrícolas

\begin{tabular}{l|c|r|r|r}
\hline \multirow{2}{*}{\multicolumn{1}{c|}{ REGİ̃O }} & \multicolumn{3}{c|}{ CONVERSÃO } & \multirow{2}{*}{ \% PROTEGIDO } \\
\cline { 2 - 4 } & Período & ha (1000) & \multicolumn{1}{c}{$\%$} & 0,36 \\
\hline Rio Grande do Sul & $1970-1996$ & -3.554 & $-25,2$ & 0,3 \\
\hline Pampa Argentina & $1988-2000$ & -924 & $-3,6$ & 0,2 \\
\hline Uruguai & $1990-2000$ & -980 & $-7,7$ & 0 \\
\hline
\end{tabular}

Geologicamente essa região é a mais antiga do Rio Grande do Sul (NESKE, 2009), sendo por isso também chamada de Escudo Cristalino Sul-Rio-Grandense. As rochas são formadas principalmente de composição granítica com associações de rochas metamórficas (STRECK apud Neske, 2009) intercaladas por estruturas areníticas de 400 a 600 milhões de anos (figura 3).

A exploração de minérios na Serra do Sudeste também transformou a paisagem, embora esta tenha sido uma atividade econômica bastante localizada. Atualmente, a exploração do calcário se faz presente no Alto Camaquã, sendo esta uma atividade extremamente impactante na paisagem, causando remoção de solo e vegetação de áreas íngremes, alterando o ciclo hidrológico e contaminando o lençol freático.

Quanto aos solos, predominam os pedregosos com afloramentos de rochas, presentes em áreas de relevo ondulado a fortemente ondulado (Neske, 2009), vulneráveis a erosão e que conferem grandes restrições ao uso agrícola. É uma região que possui solos rasos na sua maior extensão e que, de acordo com a FEPAM (2007), apresenta alta restrição para atividade silvícola que, contraditoriamente, vem sendo implantada de maneira cada vez mais intensa na região, como apontam os dados do IBGE (2007) e do próprio Zoneamento Ecológico Econômico do RS. 


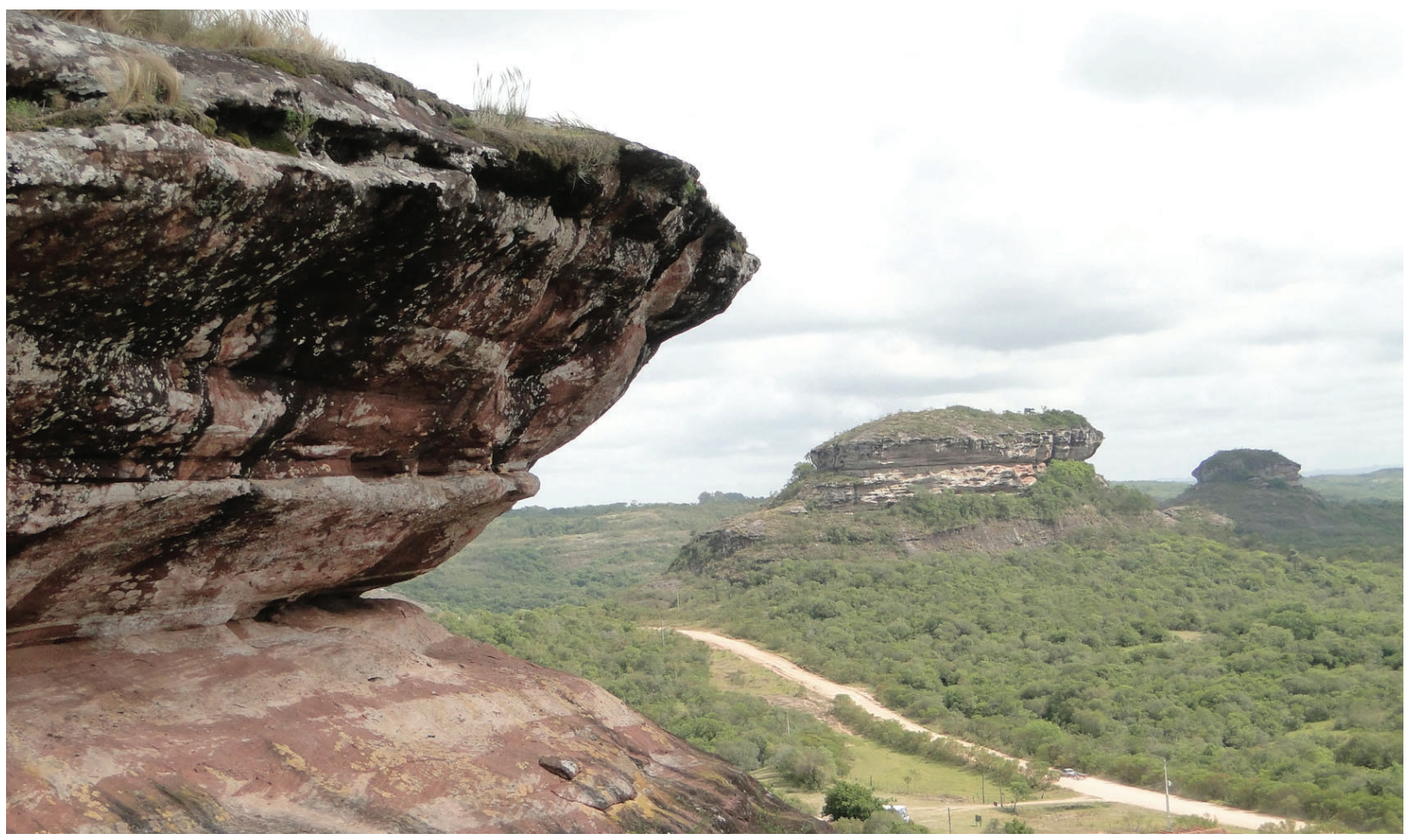

Figura 3 - Feições areníticas características da região das Guaritas no município de Caçapava do Sul. Fonte - Acervo particular de Adriano Figueiró (2010)

A restrição às atividades agrícolas contribuiu para a produção de uma clara identidade pecuária a este território, desde o início da ocupação. Para fomentar este tipo de atividade e, ao mesmo tempo, propiciar a ocupação do território, a Coroa portuguesa começou a distribuição de Sesmarias , inicialmente, para os tropeiros e militares, o que consolidou a criação extensiva de gado nos latifúndios (PESAVENTO, 1997) (Figura 4).

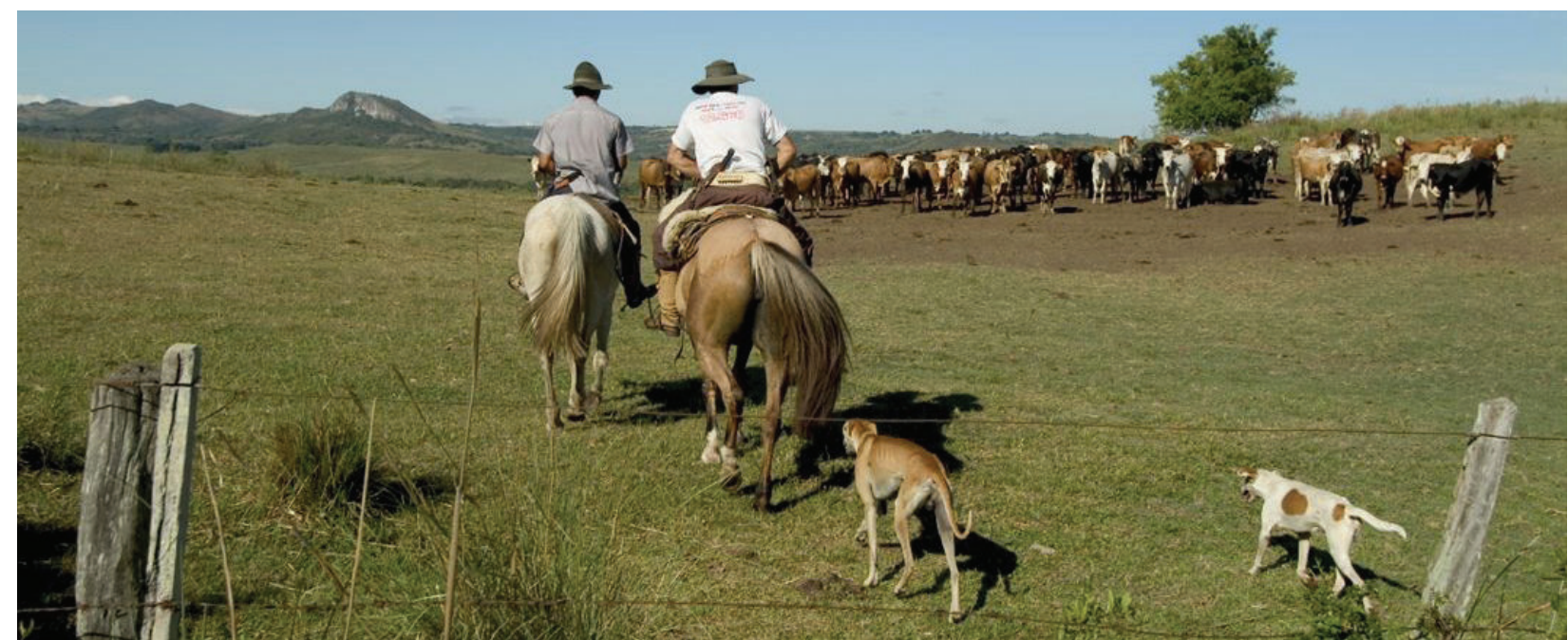

Figura 4 - Aspecto da pecuária extensiva no bioma Pampa Fonte: Backes, P. et. al. (2007)

Além da cultura e da restrição do solo, o clima também se torna um fator decisivo para a ocupação e exploração do espaço. A temperatura média anual nesta área varia entre $16 \mathrm{e} 18{ }^{\circ} \mathrm{C}$. A precipitação situa-se entre 1500 e $1600 \mathrm{~mm}$ e a hipsometria fica dentre 100 e $450 \mathrm{~m}$ (SEPLAG, 2009). O clima atual desta área é considerado úmido, não se observando a configuração de uma estação seca, o que remete a um aparente paradoxo ecológico já discutido por vários pesquisadores 
(HUECK, 1966; LINDMAN, 1906; RAMBO, 1956, apud BEHLING et. al.), pois tais condições climáticas são propícias para uma vegetação florestal e não à predominância de campos.

Estudos palinológicos (BEHLING, 2002; 2007, Lindman, 1906, apud Behling et. al. 2009) demonstram que esta é uma região que possui um histórico de paleoclimas muito significativo, além de mudanças paleoambientais e paleovegetacionais consideráveis, o que reforça mais uma vez a particularidade deste bioma.

Overbeck (2009) afirma que a vegetação característica pode ser dividida em duas categorias de campos, os campos limpos (sem componentes lenhosos) e campos sujos (campos com arbustos) além das áreas de floresta no entorno da Serra do Sudeste, numa espécie de mosaico campo-floresta (BEHLING et. al. 2009).

Nas palavras de Gassmann (2009) esses campos são de uma inacreditável riqueza de espécies cuja explicação atribui-se a sua localização de transição entre o clima tropical e temperado e, também, à variação de substrato geológico e de altitude (Overbeck, 2009). Essas condições, principalmente com relação às climáticas, vêm favorecendo a interferência antrópica na paisagem, principalmente quando da inserção das plantações de exóticas nesta área. A entrada de espécies exóticas (eucalipto, pinus, acácia negra) vem tornando-se o "problema do Pampa", como afirma Overbeck (op. cit.). O plantio de árvores nestas áreas é feito em grandes extensões, no modelo de monoculturas e vem contribuindo significativamente para a diminuição da biodiversidade do lugar.

Um destes impactos está diretamente relacionado ao grande porte das árvores que servem de matéria-prima para a produção de celulose, gerando sombreamentos que comprometem a reprodução da vegetação herbácea, tipicamente heliófila. Por isto, não é difícil concluir que a implantação de um milhão de hectares de eucaliptos e pinus sobre os campos pampeanos ocasionarão uma drástica redução populacional ou até à supressão de várias espécies de plantas, muitas das quais endêmicas e de valor medicinal com grande potencial a ser pesquisado (PICOLLI \& SCHNADELBACH, 2007).

O projeto desenvolvido pelo Instituto de Biociências da Universidade Federal do Rio Grande do Sul, em 2006, que elaborou o mapeamento da cobertura vegetal do Bioma Pampa, segundo Neske (2009), revelou que entre os tipos de formações vegetais ocorrentes nos municípios que constituem o território do Alto Camaquã, há o domínio fisionômico de uma estrutura de vegetação em transição. Ou seja, conforme, Weber \& Hasenack (apud NESKE, 2009) "são áreas de tensão ecológica com presença de formação herbáceo-arbustiva nativa com uso pecuário e floresta nativa (p.74)", o que caracteriza uma paisagem típica da Serra do Sudeste. Neske (op. cit.) aborda ainda que, de acordo com o projeto Biodiversidade do RS, a vegetação da Serra do Sudeste do Rio Grande do Sul oferece condições para uma grande diversidade da fauna, onde é possível encontrar "cervídeos, felinos silvestres, avifauna diversa e insetos, destacando-se os meliponídeos (p.75)". Segundo o projeto, a presença significante na paisagem de áreas com afloramentos rochosos oferece condições necessárias para a ocorrência de muitas espécies endêmicas junto às rochas, principalmente cactáceas. Estas, por sua vez, têm representado um importante atrativo para pesquisadores brasileiros e estrangeiros, que nos últimos anos têm protagonizado intensas atividades, que vão desde pesquisa e comércio informal, até biopirataria com as cactáceas deste bioma.

Assim, embora seja uma das regiões mais ricas em termos de biodiversidade do estado do Rio Grande do Sul, ainda existe um grande desconhecimento sobre os componentes bióticos dessa região (SEPLAG, 2009). Conforme este órgão, a Serra do Sudeste constitui um complexo mosaico de distintas formações que servem de redutos para a ocorrência de fauna e flora ameaçadas ou raras, de grande importância para a biodiversidade.

Diante do PROBio - Projeto de Conservação e Utilização Sustentável da Diversidade Brasileira, desenvolvido pelo MMA - o território do Alto Camaquã está inserido na rota de áreas consideradas pelo Ministério do Meio Ambiente (2007) como prioridade "extremamente alta" para a conservação da biodiversidade. Segundo o estudo, das espécies conhecidas, existem nessa região 2 espécies de flora ameaçadas de extinção, 8 espécies de fauna, sendo 2 mamíferos e 6 aves. 
De encontro com diversas concepções que afirmam que o homem somente contribui para a perda de biodiversidade, Overbeck (2009) e Bencke (2009) defendem que diversos fatores, naturais e antrópicos contribuem e/ou condicionam a composição da vegetação dos campos. Além do fogo e do pastejo, cabe salientar, a geada, as secas e o pisoteio por animais (domésticos ou silvestres). De acordo com os autores (op. cit.) o fogo e o pastejo são considerados, freqüentemente, os principais fatores para manutenção dos campos, visto que, na ausência destes, os campos são sujeitos ao adensamento de arbustos e, quando próximos, de vegetação florestal, devido inclusive, ao clima ser propício a formações florestais. Tal fato configura uma fortíssima interação histórica entre a apropriação da natureza, a identidade cultural cultural do gaúcho e a sustentabilidade da paisagem atual, num processo nitidamente caracterizado como co-evolutivo (GUZMÁN, 2000).

Bencke (op. cit.) afirma que a perturbação humana, principalmente com relação à fauna e flora, faz-se necessária neste ecossistema, visto que diversas espécies apenas encontram-se ali por já terem desenvolvido adaptações que necessitam de um determinado nível de perturbação para fazerem-se presentes. Além disso,

Os estudos sobre o papel dos regimes de perturbação como determinantes da diversidade da fauna tem enfocado principalmente aves, mas há evidências de que as conclusões obtidas para esse grupo são válidas também para outros grupos biológicos altamente diversificados em ecossistemas campestres, como insetos, pelo menos em regiões com histórico recente de pastejo por herbívoros nativos. Esses estudos mostram que os efeitos dos fatores de perturbação (principalmente o fogo e o pastejo) sobre a heterogeneidade espacial da vegetação influenciam fortemente a composição da avifauna. Comunidades de aves que evoluíram em ecossistemas campestres normalmente incluem desde espécies intolerantes ao fogo e ao pastejo até espécies dependentes desses fatores, que em conjunto requerem um gradiente estrutural contínuo de vegetação... (BENCKE, 2009, p 111)

Desse modo, pode-se afirmar com base em Bencke (op. cit.) que tanto a ausência de perturbação quanto o seu excesso, podem ser prejudiciais a biodiversidade de determinados ecossistemas, visto que ambas levam a redução da diversidade/riqueza, devido à perda da heterogeneidade.

Com relação à manutenção da biodiversidade, é importante salientar que também se fazem presentes na paisagem do Alto Camaquã propriedades baseadas no modelo da agricultura familiar. Isto ocorre devido ao processo de fracionamento dos campos, moldado por condicionantes de conjuntura econômica, sucessões e heranças, doações de frações para peões de confiança e filhos bastados, além da aquisição propriamente dita e de posseiros. (RIBEIRO apud NICOLA, 2004).

Este modo de produção familiar tende ainda a considerado menos degradante que os monocultivos, visto que este modo de exploração apresenta uma reduzida dependência externa dos sistemas de produção e um maior uso de fontes energéticas renováveis, permitindo a conservação da diversidade biológica e cultural.

Quanto à diversidade da produção camponesa tradicional Wanderley (1996) comenta que

O sistema tradicional de produção camponês, denominado de "policultura-pecuária" e considerado "uma sábia combinação entre diferentes técnicas", foi se aperfeiçoando ao longo do tempo, até atingir um equilíbrio numa relação específica entre um grande número de atividades agrícolas e de criação animal. Com efeito, os estudos sobre as sociedades camponesas tradicionais mostram que a evolução destas pode ser percebida através do esforço de aperfeiçoar esta diversidade, seja pela introdução de novas culturas, até o limite da supressão das áreas de pousio, seja pelo aprofundamento da relação entre as culturas e as atividades pecuárias efetuadas no estabelecimento. (WANDERLEY, 1996, p.03.)

A produção camponesa e as formas de exploração dos agroecossistemas, desenvolvidas pelos saberes tradicionais locais, manteve na região uma relação mais intensa com a natureza do que com o mercado, proporcionando uma interdependência entre produção e recursos naturais, amenizando os processos de degradação ambiental. 
Melgarejo (apud Teixeira Filho, 2009) chega mesmo a afirmar que a agricultura de pequeno porte e a reforma agrária devem ser considerados como instrumentos para a dinamização do "tecido social" e do desenvolvimento local. Reforça ainda que as condições naturais da região são propícias para cultivo de frutíferas, com ênfase na produção de vinhos finos, no cultivo de hortaliças, criação de gado - podendo, inclusive, criar núcleos produtivos para beneficiamento da produção.

Dado o grau de dependência do homem para com o meio natural nesta paisagem, nota-se uma necessidade vital de convivência que vá para além da coexistência. Nesse sentido, embora qualquer interferência humana cause algum tipo de alteração, é preciso considerar que algumas delas podem ser capazes de romper com os limites de resiliência da paisagem, os quais são descritos por Romero e Jiménez (2000) como a capacidade que a paisagem tem para absorver os transtornos e recuperar com rapidez seu estado de equilíbrio.

Por tudo o que se discutiu até aqui, é possível concluir que a grande fragilidade da paisagem do Alto Camaquã se traduz em uma baixa capacidade de resiliência frente aos impactos que hora se apresentam.

Até então, as atividades econômicas presentes, baseadas na pecuária, possibilitaram, embora com alteração, a manutenção da paisagem, a exemplo do predomínio do campo sobre a formação florestal, além da conservação da cultura local. Em contrapartida, "nunca na história desse bioma, a inserção de uma monocultura de espécies exóticas foi capaz de produzir tamanhas alterações na paisagem, dificultando sua capacidade de recuperação, visto que atividades desta natureza não possibilitam nem a manutenção dos campos e, tampouco o avanço das formações florestais nativas. Assim, a sua inserção altera profundamente tanto os elementos bióticos, abióticos quanto os antrópicos, suprimindo a diversidade ambiental e cultural do lugar.

\section{CONSIDERAÇÕES FINAIS}

A importância do estudo da paisagem do Alto Camaquã não está apenas em função das atividades atuais, mas também pela sua história e processo de ocupação. De acordo com Picolli \& Schnadelbach, (2007) devem permanecer nas coxilhas e planícies pampeanas os rebanhos que há séculos se reproduzem em suas pastagens, porém seguindo um manejo que não leve à degradação de solos e campo.

Para que esta opção se concretize muitos especialistas apontam como ideal a forma de exploração realizada pelos agricultores familiares, que apresentam uma certa autonomia em relação a organização produtiva e um baixo nível tecnológico agrícola. Esta é a razão pela qual esses agricultores familiares camponeses, optam por formas de produzir que não dependam de capital externo, mas pautadas pela família, pelos conhecimentos técnicos acumulados, pelas suas crenças, pelos seus valores culturais, tanto imateriais quanto materiais, transmitidos ao longo de gerações e que geram uma identidade territorial peculiar e que, desta forma, apresentam características potencializadoras para um real desenvolvimento. Estas características estão presentes na forma de ocupação e uso dos recursos da sub-bacia do Alto Camaquã, como demonstram as pesquisas que têm sido realizadas nesta região.

O Alto Camaquã é uma região de grande diversidade paisagística possuindo um importante patrimônio natural e histórico-natural a ser preservado e aproveitado de forma sustentável no desenvolvimento de atividades que estejam de acordo com a valorização da cultura local. A associação de elementos ambientais bióticos e abióticos do território somado a aspectos da cultura local revela uma paisagem de grande beleza cênica, conferindo ao território, um grande potencial para o aproveitamento ecoturístico.

Neste sentido, a preservação e manutenção da paisagem e biodiversidade do Alto Camaquã dependem de alternativas que contestem os impactos e as limitações advindas com os modelos de 
desenvolvimento e modernização trazidos de fora para a região, como as monoculturas silvícolas, que não estão de acordo com as potencialidades locais.

\section{REFERÊNCIA BIBLIOGRÁFICA}

ALTO CAMAQUÃ - desenvolvimento territorial endógeno. Disponível em: www.altocamaqua.org/v10. Acesso em: junho de 2009.

ARRARTE, C.P. Plantaciones Forestales e Impactos Sobre el Ciclo del Água. Un análisis a partir del desarrollo de las plantaciones forestales en Uruguay. Montevideo: Grupo Guayubira, 2007.

BERTRAND, G. Paisagem e geografia física global. Caderno de Ciências da Terra, 13. São Paulo, 1972

BACKES, P., DEL RE, F. AIGNER, E. Pampa. Ensaio Fotográfico. Brasília: MMA, 2007

BEHLING, H. et. al. Dinâmica dos campos no sul do Brasil durante o Quaternário Tardio. In PILLAR, V.P... [et. al]. Editores. Campos Sulinos: Conservação e uso sustentável da biodiversidade. Brasília: MMA, 2009. BENCKE, G. A. Diversidade e conservação da fauna nos campos do sul do Brasil. In: PILLAR, V.P... [et. al]. Editores. Campos Sulinos: Conservação e uso sustentável da biodiversidade. Brasília: MMA, 2009.

BILENCA, D.; MIÑARRO, F.. Identificación de Areas Valiosas de Pastizal en las Pampas y Campos de Argentina Uruguay y sur de Brasil. Buenos Aires: J.M. Kaplan Fund - Fundación Vida Silvestre Argentina, 2004.

Fundação Estadual de Proteção Ambiental - FEPAM e secretaria Estadual de Meio Ambiente - SEMA. Zoneamento Ambiental para atividade de silvicultura. Vol. I e II. Porto Alegre, Janeiro de 2007.

Fundação Estadual de Proteção Ambiental - FEPAM e secretaria Estadual de Meio Ambiente - SEMA. http://www.fepam.rs.gov.br/qualidade/bacia_camaqua.asp.

GASSMANN, J. A transdisciplinary approach to rural development and conservation in the Alto Camaquã basin, Rio Grande do Sul, Brazil. Master thesis in Technische Universität München. Colaboration with Universidade Federal do Rio Grande do Sul: Porto Alegre, 2009.

GUZMÁN, E. S. Sobre el campesinado, la globalización de la economía y el desarrollo rural.Córdoba: Universidad de Córdoba, 2000. Mimeo.

MARCHIORI, J. N. C. Fitogeografia do Rio Grande do Sul: Campos Sulinos. Porto Alegre: EST, 2004. In: PILLAR, V.P... [et. al]. Editores. Campos Sulinos: Conservação e uso sustentável da biodiversidade. Brasília: MMA, 2009.

NESKE, M.Z. Estilos de agricultura e dinâmicas locais de desenvolvimento Rural: o caso da pecuária familiar no território Alto Camaquã no Rio Grande do Sul, no Programa de Pós-Graduação em Desenvolvimento Rural da Faculdade de Ciências Econômicas da UFRGS: Porto alegre, 2009.

NICOLA, P. M. Ação Extensionista e Formação de Capital Social no Projeto Área Piloto - RS. Dissertação de Mestrado pela Universidade Federal de Santa Maria, 2004.

OVERBECK, G. E. et. al. Os campos sulinos: um bioma negligenciado. In: PILLAR, V.P... [et. al]. Editores. Campos Sulinos: Conservação e uso sustentável da biodiversidade. Brasília: MMA, 2009.

PESAVENTO, S. J. A história do Rio Grande do Sul. Porto Alegre: Ed. Mercado Aberto,1997.

PICOLLI, L.R., SCHNADELBACH, C. V. [coord.] O Pampa em Disputa: A biodiversidade ameaçada pela expansão das monoculturas de árvores - Amigos da Terra Brasil. Porto Alegre, 2007.

ROMERO, A.G.; JIMÉNEZ, J.M. Eı Paisaje en el Ámbito de la Geografia. Cidade do México: UNAM, 2002.

SUERTEGARAY, D.M.A., PIRES DA SILVA, L.A. Tche Pampa: Histórias da natureza Gaúcha. In: PILLAR, V.P... [et. al]. Editores. Campos Sulinos: Conservação e uso sustentável da biodiversidade. Brasília: MMA, 2009.

SEPLAG. Secretária de Planejamento e Gestão do Rio Grande do Sul. Disponível em: www.seplag.rs.gov. br/ . Acesso em: 10 jan. 2010. 
SEPLAG. Secretária de Planejamento e Gestão do Rio Grande do Sul. Projeto RS Biodiversidade: diagnóstico das áreas prioritárias. Disponível em: www.biodiversidade.rs.gov.br. Acesso em: 10 jan. 2010.

TEIXEIRA FILHO, A. Eucalipto ou pau-brasil? In: TEIXEIRA FILHO, A. (Org.). Eucalipitais: Qual Rio Grande do Sul queremos? 2008.

WANDERLEY, Maria de Nazareth Baudel. Raízes históricas do campesinato brasileiro. In: Anais XX Encontro Anual da ANPOCS. Caxambu, 1996.

Trabalho enviado em novembro de 2011

Trabalho aceito em dezembro de 2011 